\title{
Molecular physiology of crustacean and insect neuropeptides
}

\author{
Joffre Mercier, Daniel DouceT ${ }^{\dagger}$ and Arthur RETNAKARAN* \\ Brock University, St. Catherines, Ontario, L2S 3A1,Canada \\ ${ }^{\dagger}$ Great Lakes Forestry Center, Sault Ste. Marie, Ontario, P6A 2E5, Canada
}

(Received June 14, 2007)

\begin{abstract}
Organisms have to constantly respond to environmental conditions to maintain a status of dynamic homeostasis for survival. As single celled organisms evolved into multicellular animals, intercellular and inter-organ communications became indispensable not only to orchestrate homeostasis but also to control the many events punctuating metazoan development. To accomplish this need, a signal transduction system was evolved, consisting of an arborized network of nerves as well as a collection of oligopeptide neurotransmitters (neuropeptides) along with their cognate receptors. We review here the current state of our understanding of the physiology of neuropeptides in the most species-rich group of animals, the crustaceans and insects. The vast majority of neuropeptides signal through cell-surface guanosine-protein coupled receptors (GPCRs). These neuropeptide-receptor systems control a variety of physiological functions, for instance the numerous involuntary movements of internal ducts that are precisely timed for transporting reproductive, digestive and secretory materials. The rigid exoskeleton in Crustaceans and Insects require periodic molts to accomplish growth and metamorphosis and this is harmoniously regulated by a cascade of neuropeptides. Neuropeptides also regulate various events in the life of organisms including biological clocks and behavior. Technological advances in peptidomics, through the routine use MALDITOF mass spectrometry and in genomics, with in silico identification of neuropeptide receptor genes have revealed a staggering diversity of extracellular peptide-based signaling systems. This diversity underscores that communication between the afferent (nervous) system and the appropriate organs for an efferent response must be done in an unambiguous manner without any short circuits or reversal of directions. While we have a broad understanding of how neuropeptides and their receptors play a vital role in signal transduction, much of the details remain to be unraveled. (C) Pesticide Science Society of Japan
\end{abstract}

Keywords: crustacean neuropeptides, insect neuropeptides, guanosine-protein coupled receptors (GPCRs).

\section{Introduction}

One of the principal hallmarks of a living organism is its ability to respond to stimuli. As the unicellular organisms evolved into multicellular metazoans, the external signals perceived had to be transduced to several other cells requiring a neuronal network with its accompanying biochemical neurotransmitters. The progressive increase in complexity of the organisms necessitated the need for an integrated signal transducing system collecting external sensory stimuli and sending them to effector systems such that a dynamic equilibrium or homeostasis, which is essential for survival, could be maintained. During the course of evolution many advanced sense

\footnotetext{
* To whom correspondence should be addressed.

E-mail: aretnakaran@gmail.com

Published online October 9, 2007

(C) Pesticide Science Society of Japan
}

organs were developed to detect various parameters in the environment, and concomitantly different internal effector systems were formed to respond to these signals received from outside to maintain homeostasis. Coordination was achieved with a network of electrical conductors in the form of an arborized nervous system and a variety of hydrophilic biochemicals that acted as neurotransmitters carrying the sensory signals to the internal effector systems. As the animal became increasingly complex, a sophisticated neurotransmission system catering to the spatial and temporal needs during growth, development and reproduction had to be in place. Parts of the nervous tissue in many locations took on a secretory role and released protein signal transducers, the neuropeptides. A panoply of such neuropeptides exist in all organisms functioning as neurohormones, neurotransmitters or neuromodulators. Aspects of neuropeptide structure and function in insects and crustaceans have been reviewed by various authors. ${ }^{1-10)}$ The neuropeptides are ligands to their cognate receptors in the ef- 
fector systems and they function in unison to elicit a response. In recent years, with the advent of genomics and protein mass spectrometry, many of the receptors have been identified and quite a few of them have been cloned and characterized. ${ }^{11)}$ In this review, the salient features of the molecular physiology of the neuropeptide signaling systems in two of the highly successful invertebrate groups, the crustaceans and the insects will be described.

\section{Neuropeptides}

\subsection{Introduction to neuropeptides}

Among the numerous chemicals involved in the processing of information and transmission in concert with the nervous system, are a large number of oligopeptides, up to 50 amino acids in length, that are produced by neural tissue and have been collectively labeled as neuropeptides. In this review however, in the interest of preserving functional continuity, we will occasionally include a few of the larger peptides as well. Neuropeptides can (i) transmit electrical signals at the synapse and act as neurotransmitters, (ii) enhance or decrease the signal as neuromodulators, or (iii) act as neurohormones (secreted into the hemolymph in one region that initiates a specific physiological response in another). A complex protein scaffold, the harbinger of the nervous synapse, has been discovered recently in the sponges. ${ }^{12)}$ The earliest eumetazoans, the Coelenterates, formed a loose network of neurons which functioned as the primordial nervous system and there is evidence for the presence of neuropeptides even in these organisms. $^{13,14)}$

\subsection{Overview of receptors}

Response to stimuli is a characteristic shared by all living organisms and involves perception of external signals and transduction to appropriate sites for a suitable reaction. The extracellular signals are recognized by specific receptors either on the cell surface or in the nucleus, and are internalized for a response. In addition to external signals, spatial and temporal changes within the organism during growth and development have to be harmoniously regulated. This is accomplished inter alia by neuropeptides and their corresponding receptors in the effector system by a very specific biochemical lock and key mechanism. The system operates within a species in such a way that the signals cannot backtrack or become non-specific and bleed into other receptor systems. A brief classification of the receptor system is shown in Table 1 (based on refs. 15-17). The hydrophobic ligands such as steroid hormones enter the cells and bind to nuclear receptors that are essentially transcription factors whereas hydrophilic ligands such as neuropeptides bind to cell surface receptors and the signal

Table 1. Classification of Receptors in general (A) and G-protein coupled receptors (GPCRs) in particular (B) (based on refs. 15-17).

A) Classification of Receptors

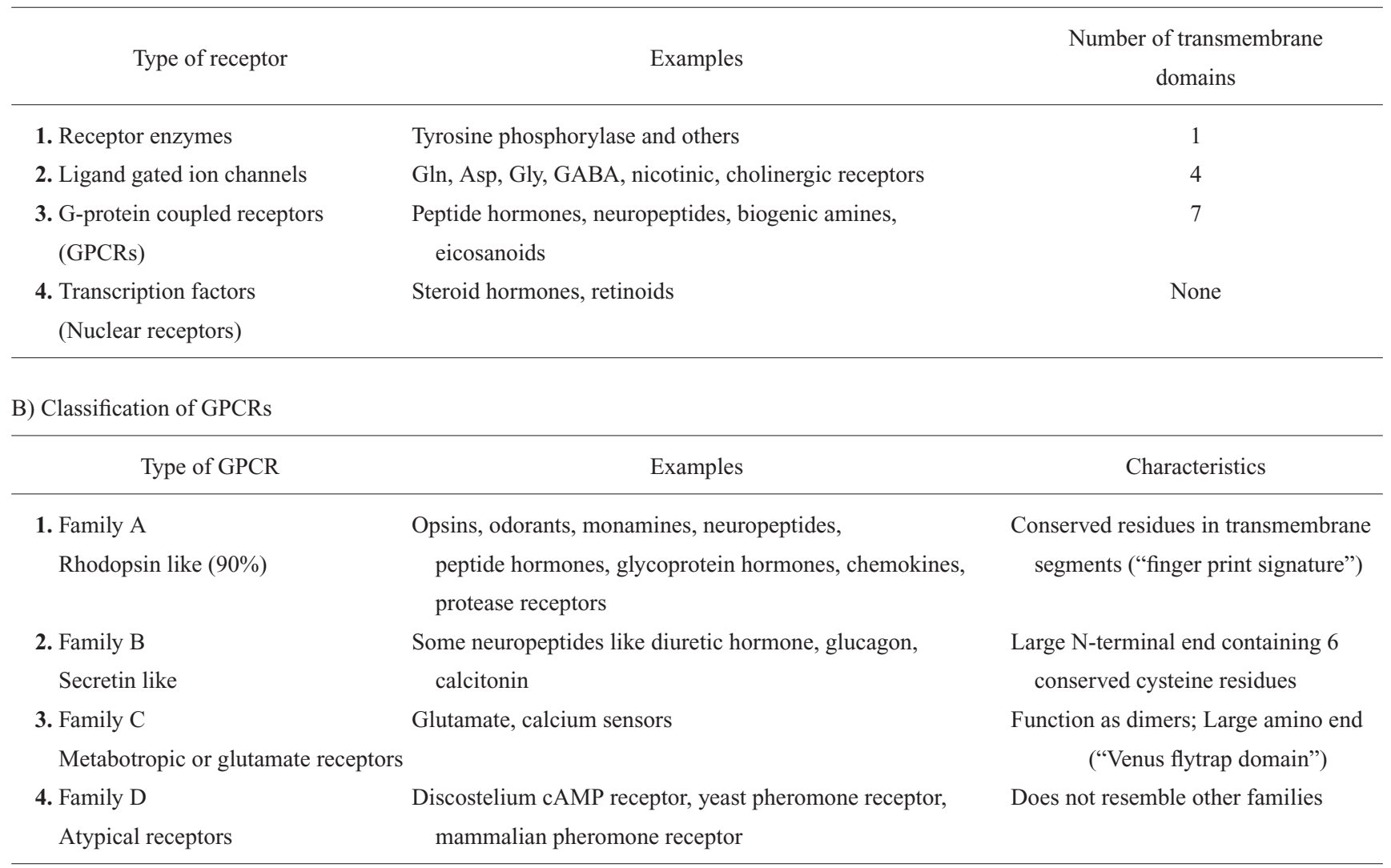


is transduced into the cells. The cell surface receptors have an external amino terminus and an internal carboxy terminus with a transmembrane region in between. Of these, the serpentine, 7-transmembrane receptors that are coupled with guanosine (GPCRs) are the ones that are utilized by most of the neuropeptides for signal transduction. The GPCRs are at present divided into 4 families based on their biochemical make-up but Family A, the rhodopsin-like GPCRs, includes over $90 \%$ of the neuropeptides. A few neuropeptides utilize Family B, the secretin-like GPCRs. Family C, the metabotropic or glutamate receptors and Family D, the atypical GPCRs are the other two groups and are shown in Table 1.

\subsection{Guanosine - protein coupled receptors (GPCRs)}

All neuropeptides and neurohormones are hydrophilic and act as extracellular signals or ligands by binding to a cell surface receptor. In mollusks, the tetrapeptide FMRFamide (Phe-MetArg-Phe- $\mathrm{NH}_{2}$ ) can directly activate a sodium channel. ${ }^{18,19)}$ In general, however, neuropeptides act via guanosine protein (G proteins) coupled receptors (GPCRs). G proteins are characterized by a signature 7 transmembrane configuration with an extracellular amino terminus and a cytosolic carboxy terminus. The $\mathrm{G}$ protein is attached to the carboxylic end in the cytosol and is made of a heterotrimeric complex, $\mathrm{G}_{\alpha}, \mathrm{G}_{\beta}$, and $\mathrm{G}_{\gamma}$ as well as guanosine diphosphate (GDP) and this configuration is considered as the resting or low affinity state. For each ligand (neuropeptide) there is a corresponding receptor located in the effector site. Once the ligand binds to the receptor, it initiates conformational changes and activates the receptor. $^{20)}$ A generalized GPCR is shown in Fig. 1 (based on refs. 16, 17). Upon binding, the receptor is activated and the GDP is replaced with a GTP, the 3 subunits separate into a $G_{\alpha}$ monomer and $\mathrm{a}_{\beta}-\mathrm{G}_{\gamma}$ dimer. In many cases, adenyl cyclase is activated which in turn leads to an increase in the second messenger, cAMP which activates protein kinase $\mathrm{C}$ (PKC). PKC phosphorylates several substrates and together with the the $G$ protein dimer, $\mathrm{G}_{\beta}-\mathrm{G}_{\gamma}$, results in the cell response. In other cases, other second messenger systems, such as inositol trisphosphate $\left(\mathrm{IP}_{3}\right)$ and diacylglycerol (DAG) appear to be involved. ${ }^{16,17,21)}$

\subsection{Life cycle of a generalized, canonical GPCR}

A generalized, canonical cartoon describing the life history of a typical GPCR is shown in Fig. 2. The progressive changes to the GPCR are described in 5 stages. Stage 1 shows the inactive or resting state where the heterotrimeric G-protein and the ligand (or agonist which is the neuropeptide) have not bound to the 7-transmembrane protein. Stage 2 is the beginning of activation where the ligand has bound to the extracellular amino terminus and the heterotrimeric-GDP protein is bound to the carboxy terminus. Stage 3 is the active state where GTP has exchanged for GDP. Stage 4 is the desensitized stage where the G-protein has dissociated into 2 units, the carboxy terminus is phosphorylated which enables it to bind to $\beta$ arrestin, a promiscuous, cytoplasmic scaffolding protein. Stage 5 is the internalization of the transmembrane domain and subsequent degradation followed by resynthesis of the GPCR. Further details are described in the Fig. 2 legend (After refs. 16, 17, 20, 22, 23).

\subsection{Molt inhibiting Hormone (MIH) as an example to il- lustrate the mode of action of a neuropeptide with its cognate receptor}

To illustrate the neuropeptide-GPCR function, the molecular physiology of the Molt Inhibiting Hormone (MIH) is described. Recently the signal transduction in the crustacean molting gland was elucidated in the land crab, Geocarcinus lateralis. ${ }^{24)}$ The $\mathrm{Y}$ organ (YO) in the cephalothorax of this decapod synthesizes ecdysteroids and initiates the molting process similar to what is known in insect systems. ${ }^{25)}$ The $\mathrm{X}$ organ or Sinus gland complex (XO/SG) located in the eyestalk ganglia secretes 2 neuropeptides, the molt inhibiting hormone (MIH) and the crustacean hyperglycemic hormone $(\mathrm{CHH})$, and both of them appear to inhibit ecdysteroid synthesis by the Y organ. The MIH inhibition occurs through a GPCR. Upon binding with the receptor the G protein complex activates adenyl cyclase which produces the second messenger cAMP, which in turn activates the protein kinase A (PKA). PKA opens calcium channels and allows the entry of extracellular $\mathrm{Ca}^{2+}$, which binds to calmodulin (CaM). CaM then activates calcineurin, a CaM-dependent phosphatase, which dephosphorylates nitric oxide synthase (NOS) and makes it active. The NOS catalyzes the conversion of arginine to citrulline and nitric oxide (NO). The NO activates the NOsensitive guanyl cyclase which converts GTP to cGMP, which activates a cGMP-dependent protein kinase (cGPK). The cGPK inhibits the expression of ecdysteroidogenic proteins, and this effect turns off ecdysteroid production. Ablation of the eye stalk results in the removal of $\mathrm{MIH}$ and $\mathrm{CHH}$, which results in ecdysteroid production and initiation of molting (Fig. 3). ${ }^{24)}$

\section{Neuropeptides of Crustaceans and Insects}

\subsection{Neuropeptide identification}

Neuropeptides are ubiquitous, pleotropic and in many instances vary from species to species making it extremely difficult to create a logical classification system for this group of very important signal peptides. ${ }^{726)}$ Almost all the neuropeptides that have been described have been detected, identified and localized using antibodies which may not unequivocally prove the presence of the neuropeptide in question because of cross reactivity between antigenically related forms. In recent years, with the advent of matrix assisted laser desorption ionization time-of-flight mass spectrometry (MALDI-TOF-MS) protein identification has become more precise. The neuropeptides from the retrocerebral complex of Manduca Sexta have been characterized by MALDI-TOF mass spectrome- 


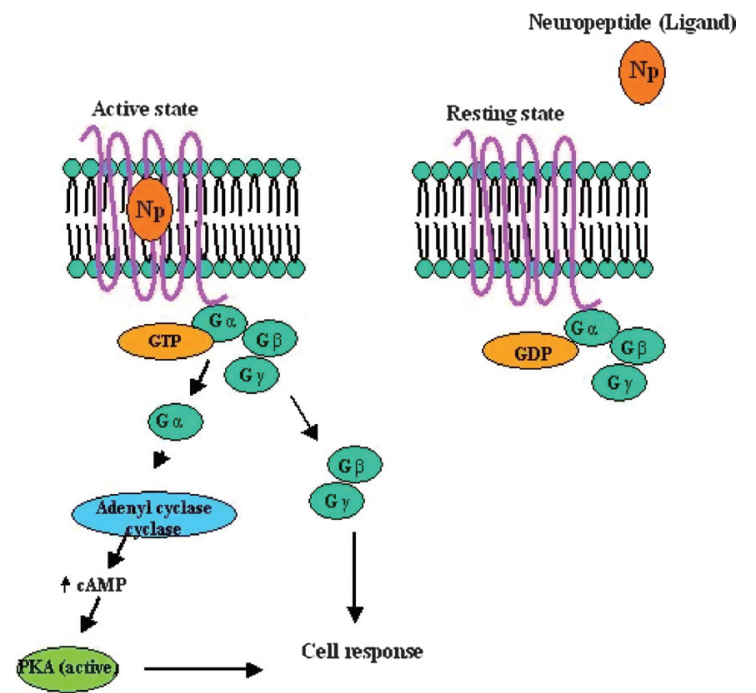

Fig. 1. Generalized example of GPCR signaling. A seven transmembrane protein in the plasma membrane with an amino extracellular end and a cytosolic carboxy end attached to a trimeric peptide (G$\alpha \beta \gamma$ ) and a guanosine (GDP) residue is the basic structure in the resting state. When a neuropeptide $(\mathrm{Np})$ binds to the receptor, a chain reaction is initiated (based on refs. 16, 17). try. $^{27,28)}$ Isolation methods have also benefited from improvements in extraction procedures such as the use of anticoagulants (e.g. citrate) to increase peptide recovery. ${ }^{29)}$ Using some of the information on structural characteristics and primary functions, the neuropeptides of crustaceans and insects have been grouped into families (Table 2) (based on refs. 30, 1, 2, $7,10)$.

\subsection{Identifying cognate GPCRs for neuropeptides}

Neuropeptides transduce their extra cellular signal through their cognate GPCR into the cell which results in a specific effector response. It becomes readily apparent that neuropeptides have to be studied along with their receptors to elucidate their response. With the total genome sequencing of several insects, in silico detection of GPCRs has become possible. Hauser et al. ${ }^{3,4)}$ report that their group found 44 neuropeptide receptors in the fruit fly, Drosophila melanogaster and 35 in the honey bee, Apis mellifera genomes. GPCRs for neuropeptides have co-evolved with their ligands whereas the GPCRs for biogenic amines often bind to the same biogenic amines over the course of evolution. Ligands have been found for many GPCRs that were formerly considered as orphan recep-

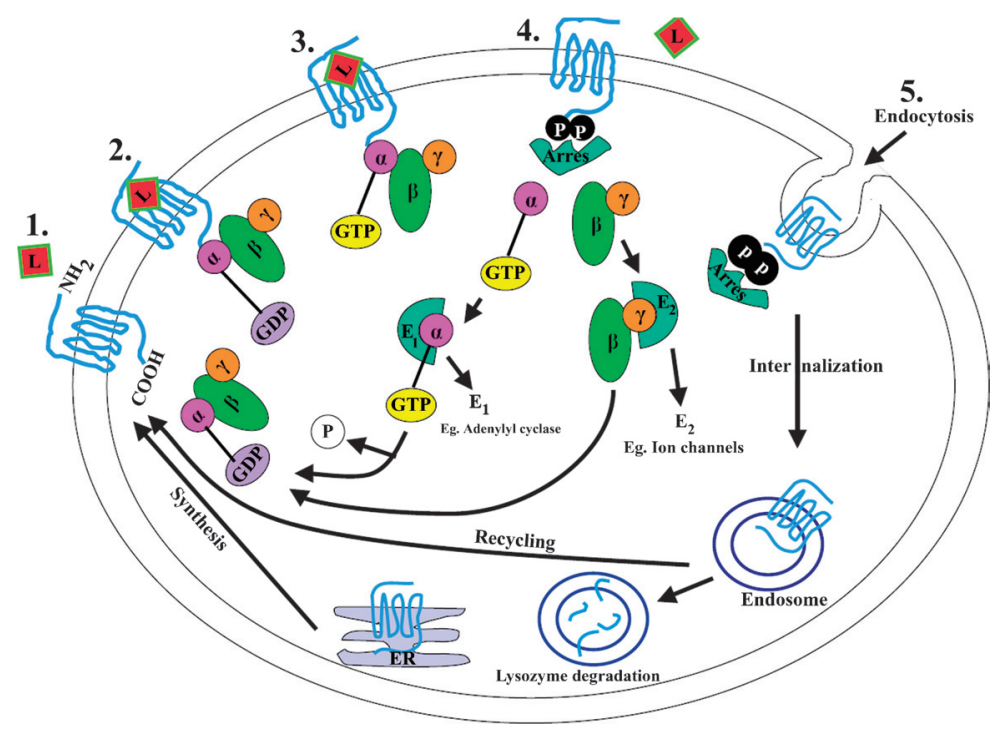

Fig. 2. Canonical representation of GPCR life cycle. [1.] The three partners in the receptor complex in an inactive state are (i) the free ligand (L) or agonist that lies outside the cell, (ii) a serpentine G-protein coupled receptor (GPCR) consisting of 7 transmembrane domains with an extracellular amino end and an intracellular carboxy end, and (iii) an unbound trimeric G-protein with an $\alpha$ subunit which has GTPase activity and an attached GDP as well as a $\beta$ and $\gamma$ subunits. [2.] The ligand binds to the transmembrane region of the GPCR which creates a conformational change in the carboxy end enabling the $\alpha$ subunit of the trimeric G-protein to bind to the receptor. [3.] Binding reduces the affinity for GDP which is exchanged for a GTP and the receptor becomes active. [4.] The G-protein dissociates into an $\alpha$ subunit with the GTP which combines with a membrane bound effector $\left(\mathrm{E}_{1}\right)$ such as adenyl cyclase and initiates a cellular response and a $\beta$ - $\gamma$ subunit which combines with another membrane bound effector $\left(\mathrm{E}_{2}\right)$ such as an ion channel regulator initiating another cellular response. The $\alpha$ subunit loses a P and the GTP once again becomes GDP and together with the $\beta-\gamma$ subunit form the inactive G-protein complex for the next activation cycle. The carboxy terminus of the GPCR is phosphorylated by promiscuous GPCR kinases (also called GRKs), which makes it possible for another promiscuous cytoplasmic protein, arrestin (Arres) to bind to the carboxy end blocking the G-protein binding site. As a result the GPCR is desensitized. The ligand leaves the receptor. [5.] The desensitized GPCR is internalized by endocytosis into a clathrin coated vesicle and is either degraded by lysozyme or recycled. Also, new GPCRs are synthesized in the endoplasmic reticulum (ER). (Based on refs. 16, 17, 20, 22, 23). 


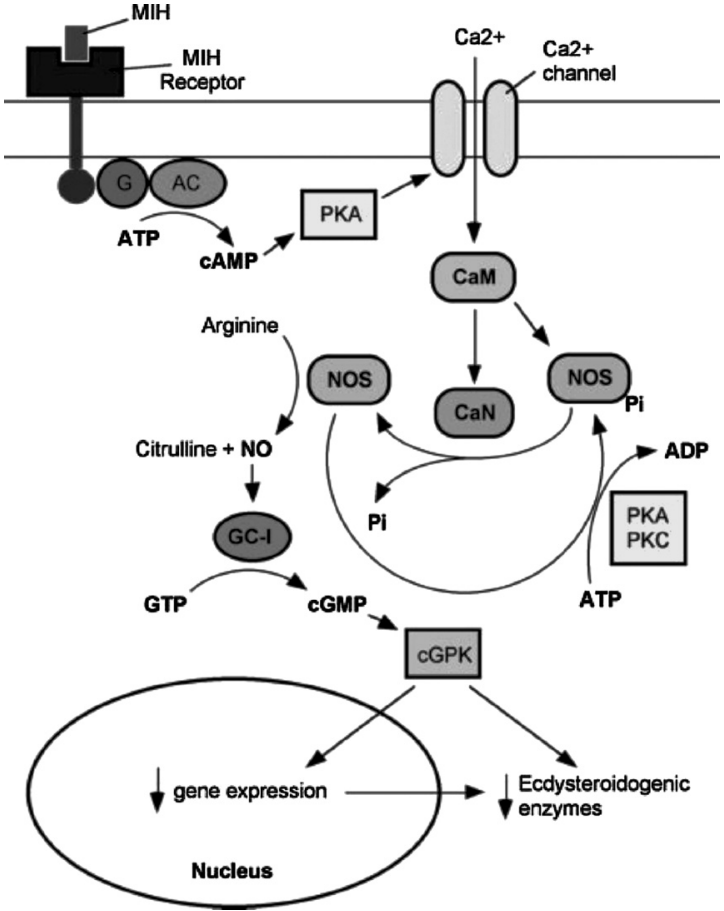

Fig. 3. Hypothetical MIH signaling pathway in the crustacean molting gland (Y-organ). MIH binds to a G protein-coupled receptor, activating adenylyl cyclase (AC); intracellular $\mathrm{Ca}^{2+}$ rises when protein kinase A (PKA) activates a membrane $\mathrm{Ca}^{2+}$ channel; NO synthase (NOS) is activated when $\mathrm{Ca}^{2+} /$ calmodulin (CaM) binds and NOS is dephosphorylated by calcineurin $(\mathrm{CaN}), \mathrm{a} \mathrm{Ca}^{2+} /$ calmodulindependent phosphatase; NO activates a NO-sensitive (class I) guanylyl cyclase (GC-I). Activation of a cGMP-dependent protein kinase (cGPK) inhibits expression and/or activities of ecdysteroidogenic proteins, resulting in reduced ecdysteroid synthesis. NOS is inactivated by phosphorylation by PKA, protein kinase $\mathrm{C}$ (PKC) and/or other protein kinases. The model predicts that NOS is in a dephosphorylated state in the inactive YO from intact intermolt animals; reduction in circulating MIH by ESA results in NOS phosphorylation in the activated YO (reproduced with permission from the authors and the journal ${ }^{24)}$ ).

tors and have been deorphanized. Using the transmembrane conserved motif several GPCRs have been identified within the annotated genes from Drosophila and they fall under the 4 families, Family A, rhodopsin-like, Family B, secretin-like, Family C, glutamate receptor-like, and Family D, atypical receptors. At least 44 were determined to be neuropeptide receptors and 21 were neurotransmitter receptors. More recently some 200 genes have been identified as coding for the Drosophila GPCRs. ${ }^{4)}$

\subsection{Neuropeptides of crustaceans and insects}

We will attempt to describe what is known about the physiology of each neuropeptide along with its cognate receptor, if it is known, to provide as complete a picture as possible after providing an outline of the various families of neuropeptides in crustaceans and insects.

\subsection{Adipokinetic hormone (AKH) / red-pigment concen- trating hormone (RPCH)}

These neuropeptides are 8-10 amino acids in length and blocked at the N-terminus with pyroglutamate (pGlu) and at the C-terminus with an amide. The red-pigment concentrating hormone (RPCH) was sequenced from the shrimp Pandalus borealis in 1972 and subsequently the adipokinetic hormone $(\mathrm{AKH})$ was isolated from the locust, Locusta migratoria. ${ }^{31,32)}$ Both peptides are produced as preprohormones with a signal sequence and are cleaved successively to form the prohormone and the active, circulating hormone. Having highly conserved in sequences, RPCH and AKH show cross-reactivity during immunodetection with antibodies. AKH, however, has so far only been found in insects.

$\mathrm{RPCH}$ receptors are present in the epidermal chromatophores where they can concentrate the pigment to make the organism intensely red. The receptors are also present in the stomatogastric system. AKH receptors are present in the insect's fat body where, upon binding of $\mathrm{AKH}$, they provoke the release of fatty acids to create a hyperlipaemic effect. $\mathrm{AKH}$ can also generate hypertrehalosemia by activating fat body glycogen phosphorylase. AKH receptors have been identified in the genomes of the fruit fly, D. melanogaster, the silkworm, Bombyx mori and the honey bee, A. mellifera. ${ }^{3,4,33)}$ The honey bee sequence has $57 \%$ identity with the fruit fly $\mathrm{AKH}$ receptor. In vivo, $\mathrm{AKH}$ receptors have been detected in the pterothoracic ganglion (fused meso- and metathoracic ganglia) of M. Sexta. ${ }^{34)}$

The physiology of AKH has been well studied in L. migratoria. ${ }^{35)}$ Three AKHs (I, II, and III) are synthesized and stored in the glandular cells of the corpora cardiaca and released during flight to provide instant energy in the form of diacyl glycerol (DAG) to the flight muscle. An efficient lipophorin shuttle mechanism in the hemolymph carries the DAG from the fat body to the flight muscle. While trehalose from the glycogen is also mobilized, it is the fat reserves that provide the bulk of the energy (Fig. 4). ${ }^{35)}$ The cockroach AKH (also designated as neurohormone D) is an octapeptide, pQVNFSPNWamide and modulates $\mathrm{Ca}^{2+}$ and $\mathrm{Na}^{+}$currents in the dorsal unpaired median neuron. ${ }^{36)}$

\subsection{Pigment dispersing hormone (PDH) / pigment dis- persing factor (PDF)}

Like RPCH/AKH, these peptides are synthesized as preprohormones with a signal peptide and are processed to form the active hormone. PDH is an octapeptide that disperses the red pigment in the epidermal chromatophores of crustaceans and is antagonistic to RPCH. It also has a role in locomotor activity and as a circadian pace maker. ${ }^{37)}$ The N-terminus of PDH is free but the C-terminus is amidated. PDF is structurally similar to PDH but found only in insects. In addition, PDF has activities unrelated to pigmentation, being involved mostly in circadian rhythmicity. ${ }^{7)}$ PDF receptors have been identified in silico in the Drosophila and honey bee genomes., ${ }^{3,4}$ 
Table 2. Outline of insect and crustacean neuropeptide families (based on refs. 1, 2, 7, 10, 30)

\begin{tabular}{llll}
\hline \# in & Neuropeptide family & Chacteristics & Primary functions \\
text & &
\end{tabular}

2.4 Adipokinetic hormone (AKH) / red-pigment 8-10 aa; blocked N-terminus (pyroglutamate) Mobilizing lipids; redistributing red pigment concentrating hormone $(\mathrm{RPCH})$ and C-terminus (amide)

2.5 Pigment dispersing hormone (PDH) /

8 aa; free N-terminus; blocked C-terminus;

Pigment dispersal, biological clock, Pigment dispersing factor (PDF) several conserved residues circadian pace maker

2.6 Allatostatins (AST) and allatotropins (ATs)

ASTs have YXFGLamide C-terminus and are of 3 types. ATs have a sequence of APFRNSEMMTARG Famide;

ASTs are JH inhibitory, myoinhibitory, and vitellogenesis inhibitory

ATs present in several invertebrates, stimulate JH synthesis; also myotropic.

2.7 Crustacean hyperglycaemic hormone (CHH) 72 aa; 6 cysteine residues; 3 conserved Mobilizes glucose from hepatopancreas disulfide bridges; blocked and unblocked isoforms

2.8 Amnesiac

2.9 Cardioactive peptide (CAP) and periviscerokinins (PVK)

2.10 Corazonin (CRZ)

2.11 Crustacean cardioactive peptide (CCAP); eclosion hormone $(\mathrm{EH})$ and eclosion triggering hormone $(\mathrm{ETH})$

2.12 Diuretic hormone / corticotropin releasing factor (CRF) like / calcitonin like

2.13 Ecdysis motor behavior such as PTTH, EH, PETH, ETH, CCAP, Corazonin

2.14 FMRFamides (3 types)

2.15 Neuropeptide F-like (NPF) peptide / neuropeptide Y-like (NPY) peptide

2.16 Ion transport peptide (ITP)

2.17 Leucokinins

2.18 Pyrokin related peptides (PK) such as locust myotropin, pheromone biosynthesis activating neuropeptide (PBAN), diapause hormone (Bom-DH), melanization and reddish coloration hormone (MRCH).

2.19 Tachykinin related peptides (TRPs)

2.20 SIFamide peptide
Product from the amn gene

FRRV conserved

Shares some sequence identity with AKH

Sequence resembles PVKs

41-47 aa (CRF like); 31 aa (Calcitonin-like) Malpighian tubule secretion

ETH has a PRLamide tripeptide C-terminus. Sequential eclosion behavior
Heptapeptides; FMRF amide C-terminus

36-39 aa; GRPRF amide C-terminus
Myotropic

Neuromodulator of feeding and digestion
Sequence similar to $\mathrm{CHH}$ and molt inhibiting Transport of $\mathrm{Cl}^{-}$ions across the hindgut hormone (MIH). Locust ITP has 72 aa.

Isolated from Leucophaea brain but found in Myotropic-hindgut and oviduct insects and crustacean brains and ganglia. C-terminus has $\mathrm{FX}_{1} \mathrm{X}_{2} \mathrm{~W}$ where $\mathrm{X}_{1}$ is contraction; secretory in Malpighian tubules

$\mathrm{F}, \mathrm{H}, \mathrm{N}, \mathrm{S}$ or $\mathrm{Y}$ and $\mathrm{X}_{2}$ is $\mathrm{A}, \mathrm{P}$ or $\mathrm{S}$.

C-terminus FXPRLamide

Muscle contraction, pheromone biosynthsis, egg diapause induction, melanization
C-terminus sequence consists of

$\mathrm{FX}_{1} \mathrm{GX}_{2}$ Ramide where $\mathrm{X}_{1}$ and $\mathrm{X}_{2}$ are variable residues.

PPFNGSIF amide, unrelated to others
Gastrointestinal and vascular function, muscle contraction, malpighian tubule secretion

Myotropic on oviduct 
Table 2. Continued.

\begin{tabular}{|c|c|c|c|}
\hline $\begin{array}{l}\# \text { in } \\
\text { text }\end{array}$ & Neuropeptide family & Characteristics & Primary functions \\
\hline 2.21 & $\begin{array}{l}\text { Insulin-like peptide (produced by } \\
\text { neurosecretory cell and neurons) }\end{array}$ & Activates MAPkinase & Development and growth processes \\
\hline 2.22 & Proctolin & RYLPT sequence & Modulates visceral and skeletal muscles \\
\hline 2.23 & Arginine-vasopressin like peptide (AVP) & $\begin{array}{l}\text { CLITNCPRGamide, disulfide bridges to } \\
\text { form a homodimer }\end{array}$ & Weakly diuretic in Locusta \\
\hline 2.24 & Orkokinins (ORKs) & $\begin{array}{l}\text { In brains of insects and crustaceans; } \\
\text { Sequence-NFDEIDRSGFGFN in } \\
\text { crustaceans and NFDEIDR in insects }\end{array}$ & Myotropic \\
\hline 2.25 & Neuroparsins (NPs) & $\begin{array}{l}\text { 8-kDa neuropeptide from the pars } \\
\text { intercerebralis and corpus cardiacum }\end{array}$ & $\begin{array}{l}\text { Anti-JH, antidiuretic, neuritogenic, } \\
\text { reproduction, interact with insulin related } \\
\text { peptides }\end{array}$ \\
\hline
\end{tabular}

\subsection{Allatostatins(ASTs) and allatotropins (ATs)}

Allatostatins (ASTs) are small, 5 to 30 amino acid long neuropeptides that occur in three different forms ${ }^{38)}$ : type $\mathrm{A}, \mathrm{B}$, and C. Type A ASTs have a consensus Y/FXFGL/Iamide blocked C-terminus sequence and are found in both insects and crustaceans. Types B and C, with the consensus sequences $\mathrm{WX}_{6}$ Wamide and PISCF, respectively, occur only in insects. In several insect species ASTs inhibit juvenile hormone $(\mathrm{JH})$ production by the corpora allata and in some cases they also inhibit vitellogenesis. The allatostatic role of ASTs is not universally conserved across species, however. Type A for instance inhibits JH production in cockroaches but not in diptera. Similarly AST-C is allatostatic in Manduca but not in non-lepidopteran insects. ASTs are usually referred to as brain-gut peptides because of their myoinhibitory effect on insect visceral muscle. In crustaceans, ASTs have been shown

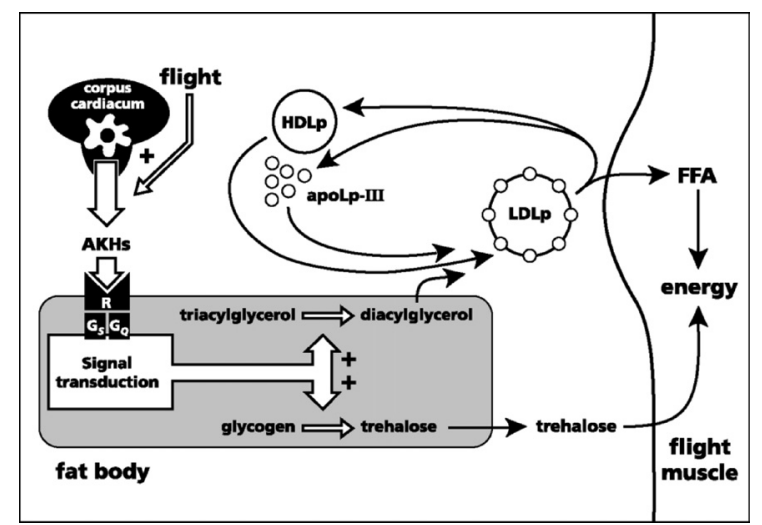

Fig. 4. Schematic overview of AKH-controlled substrate mobilization from locust fat body during flight activity. AKHs: adipokinetic hormones; R: receptor; G: G-protein; HDLp: high-density lipophorin; LDLp: low-density lipophorin; apoLp-III: apolipophorin III; FFA: free fatty acids (reproduced with permission from the authors and the journal ${ }^{35)}$ ). to act primarily as neuromodulators of stomach muscle contraction, such as in the crab Cancer borealis ${ }^{39)}$ and in the crayfish Orconectes limosus. ${ }^{40)}$ In $C$. borealis, ASTs can be detected in the stomatogastric ganglion. ASTs seem to have a more obscure role on the synthesis of methyl farnesoate (MF), the functional equivalent of $\mathrm{JH}$ in crustacea. Diploptera punctata (cockroach) ASTs could stimulate MF production by the mandibular organ (MO) of the crayfish Procambarus clarkii, thus having the opposite effect of insect ASTs. ${ }^{41)}$ Further experiments using native crustacean ASTs will shed more light on their anti- or pro-juvenelizing effects.

Receptors for type A, B, and C allatostatins have been characterized in insects. DAR 1 and 2 have been identified in the Drosophila genome and act as receptors for AST type A. Two type $\mathrm{C}$ allatostatin receptors have also been found in the Drosophila genome but only one in the honey bee genome. , $^{3,10)}$

Allatotropins (ATs) are multifunctional 13-14 amino acid long peptides found in several invertebrate groups. ${ }^{42)}$ In lepidoptera, they have a prominent role in the stimulation of $\mathrm{JH}$ biosynthesis, either during larval or adult stages, or both in some species. $^{43)}$ The same AT sequence, APFRNSEMMTARGFamide, has been obtained from cDNA or protein extracts from various moth species, including M. sexta, ${ }^{44)}$ Samia cynthia ricini, ${ }^{45)}$ Pseudaletia unipuncta, ${ }^{46)}$ and Spodoptera frugiperda. ${ }^{47)}$ A highly similar AT has also been characterized in the mosquito Aedes aegypti (Aedes-AT) and displays agespecific effects on the production of JH-III by corpora allata. Aedes-AT can trigger the production of high levels of JH-III in newly emerged females, when applied together with farnesoic acid (FA). However, in the corpora allata (CA) from older females, AT does not show such a synergistic effect. ${ }^{48)}$

Other physiological roles of ATs include the contraction of oviducts in L. migratoria by the male-synthesized Lom-AGmyotropin. ${ }^{49)}$ This peptide differs only at positions 6-8 rela- 
tive to Manse-AT and therefore can be considered part of the AT family. Lom-AG-myotropin is also active on the hindgut, but at much higher concentrations. Manse-AT has also been shown to inhibit the active transport of ions across the midgut of Manduca larvae. ${ }^{50)}$ So far no AT receptor has been found in insects and much remains to be done to determine the physiological function of ATs in other invertebrate groups, including crustaceans.

\subsection{Crustacean hyperglycemic hormone (CHH) and re- lated neuropeptides}

This family includes $\mathrm{CHH}$, the molt inhibiting hormone (MIH) and the vitellogenesis inhibiting hormone (VIH), and all three were thought to be found exclusively in crustaceans until recently. They are synthesized by the large perikarya in the X-organ in the eyestalk of decapods and are axonally transported to the sinus gland a neurohemal organ, where they are stored prior to release. $\mathrm{CHH}, \mathrm{MIH}$ and $\mathrm{VIH}$ are $72-78$ amino acids long, have 3 disulfide bridges and both ends are unblocked in most of the isoforms. ${ }^{51)} \mathrm{CHH}$ mobilizes glucose from the hepatopancreas and hence has a diabetogenic function. VIH and MIH show closer homology than either one of them to $\mathrm{CHH}^{52,53)} \mathrm{VIH}$ is a hyperglycemic hormone which also inhibits ecdysteroid synthesis and ovarian development. It is in addition important in stimulating the secretion of other hormones (thus acting as a secretagogue). MIH acts on the Yorgan in the cephalothorax of decapods and inhibits ecdysteroidogenesis and prevents molting. The mandibular organ inhibiting hormone (MOIH), a member of the MIH group, inhibits the production of MF. In view of the high sequence homology, overlapping biological effects have been reported. ${ }^{54)}$ The sole insect representative of this family is the ion transport peptide (ITP, see Section 2.16) which transports $\mathrm{Cl}^{-}$ across the ileum and sequence-wise is closer to $\mathrm{CHH}$.

\subsection{Amnesiac gene derived neuropeptide (AMN)}

The amn gene is expressed in the dorsal paired median (DPM) neurons innervating the mushroom bodies in the brain of Drosophila. The AMN neuropeptide is linked to memory retention and ethanol sensitivity in flies. It also appears to modulate calcium oscillations in the mushroom body. It is similar to the mammalian pituitary adenyl cyclase activating peptide (PACAP). ${ }^{55)}$

\subsection{Cardioactive peptide (CAP) / periviscerokinin (PVK)}

Cardioactive peptide (CAP2b) has been isolated from Manduca and Drosophila and acts as a cardioaccelerant in the former and as a Malpghian tubule secretion stimulant in the latter. ${ }^{57)} \mathrm{CAP} 2 \mathrm{~b}$ is secreted by the neurosecretory cells in the abdominal ganglia and released through the median nerve of the perisympathetic system.

Periviscerokinins (PVK) were originally isolated from the abdominal perivisceral or perisympathetic organs (PSOs). ${ }^{57)}$ The cockroach Leucophaea maderae PVK has the sequence
GSSGMIPFRRVamide and shares much of it with CAP2b indicating an ancestral relationship.

\subsection{Corazonin (CRZ)}

Corazonin (CRZ) is produced by the lateral brain neurosecretory cells projecting into the corpora cardiaca of many insects such as Periplaneta americana, Drosophila, Gryllus bimaculatus, and B. mori as well as in a few neurons in the brain. It stimulates heart rate in the cockroach, stimulates the contraction of hyperneural muscles and acts as a pigmentation-controlling factor in locusts. ${ }^{58)}$ It is best known however as an initiator of the ecdysis behavior, by stimulating the release of preecdysis- and ecdysis-trigerring hormone (PETH, ETH, see below) ${ }^{59,60)} \mathrm{CRZ}$ shares sequence homology with both $\mathrm{AKH}$ and the hypertrehalosemic hormone (HTH) to which it is probably ancestrally related. The CRZ receptor has been isolated in both Drosophila (DrmCRZR) and $M$. sexta (MasCRZR). ${ }^{59)}$

\subsection{Crustacean cardioactive peptide (CCAP)}

CCAP was first isolated as a cardioacceleratory peptide from the pericardial organs of the crab, Carcinus maenas. ${ }^{61)}$ In insects it has been identified in locusts and Manduca. It is present in the brain and in the ventral nerve cord as well as in the endocrine cells of the midgut. Its receptor has been identified in Drosophila. ${ }^{62)}$ The endocrine functions of CCAP involve the regulation of ecdysis behavior (along with EH, PETH and $\mathrm{ETH}$, see section below) and the possible control of AKH release. ${ }^{63)}$

\subsection{Diuretic hormones (DH)}

Diuretic hormones (DHs) promote fluid secretion by Malpighian tubules and assist in the formation of urine. In Drosophila 4 genes encoding precursors of DHs have been identified $^{33)}$ : i) a leukokinin-like peptide, ii) a corticotropin releasing factor-like peptide (CRF-like), iii) a calcitonin-like peptide, and iv) a cardioacceleratory peptide (CAP3b). The latter has also been identified in Manduca.

The CRF-like diuretic peptide was first isolated and sequenced from larval head extracts of $M$. sexta (named $\mathrm{MasDH})$. It is a 41 residues, C-terminally amidated peptide that has $29-35 \%$ sequence identity with the vertebrate CRF family of peptides. ${ }^{64)}$ Insect DHs are produced by the median neurosecretory cells (MNC) as well as neurosecretory cells in the abdominal ganglia. Axons from these regions reach the corpora cardiaca and perisympathetic organs and other neurohemal release sites. Fluid secretion is closely linked to cyclic AMP production by the action of MasDH. ${ }^{65)}$ While most neuropeptides use a Family A or rhodopsin-like GPCR as receptors, the CRF-like DH acts through a Family B or secretin like GPCR. ${ }^{1)}$

The calcitonin-like DH is a 31 residues peptide closely related to the mammalian calcitonin family of peptides. It was first isolated from cockroach (D. punctata), and induces 
Malpighian tubule secretion by acting through a membrane VATPase via cyclic AMP. ${ }^{66)}$

\subsection{Ecdysis motor behavior controlling peptides: PTTH, EH, PETH, CCAP, and Corazonin}

The ecdysis behavior is a classic example of the harmonious orchestration of a cascade of events regulated in part by neuropeptides. ${ }^{59,60,67-70)}$ To truly understand the ecdysis behavior we have to examine the raison d'etre of the molting process. Insects and crustaceans have a rigid exoskeleton and therefore to accommodate growth they have to periodically shed the exoskeleton and replace it with a new one. When the insect reaches a critical size, proprioreceptive signals from the gut wall are sent to the 2 pairs of dorso-lateral neurosecretory cells in the brain. These cells produce the prothoracicotropic (PTTH) hormone which is axonally conducted to the corpora allata from where it is released into the blood. Circulating PTTH reaches the prothoracic gland and through its receptor (PTTHR) induces the gland to secrete the molting hormone ecdysone which is monooxygenated to the active form, 20 hydroxyecdysone (20E). During each instar, upon reaching a critical size, a pulse of $20 \mathrm{E}$ is released to initiate the molting process. During the rise of the $20 \mathrm{E}$ peak, the hormone binds first with a heterodimeric nuclear receptor (EcR and USP), and then with a ecdysone response element (EcRE) and upregulates a set of molt initiating transcription factors. ${ }^{25,71,72)}$ The larva stops feeding, the old cuticle is digested by the secretion of the molting fluid and separates from the epidermis and concomitantly a new cuticle is synthesized underneath. All these changes happen during the rise of the $20 \mathrm{E}$ peak which is the up-regulatory phase of molting. At the same time many of the neuropeptides involved in ecdysis are synthesized and stored. For instance the 2 pairs of ventromedial neurosecretory cells in the brain secrete eclosion hormone $(\mathrm{EH})$ which is transported to the paired proctodeal nerves where it is stored. In order for the molting process to continue the $20 \mathrm{E}$ should be cleared which is what happens during the fall of the $20 \mathrm{E}$ peak. Now a set of downregulated genes are expressed which initiates ecdysis (Fig. 5).

In addition to $\mathrm{EH}$, several neuropeptides participate in the ecdysial process. There are 9 pairs of epitracheal glands located near the prothoracic spiracle and the first 8 abdominal spiracles in Manduca. Within each epitracheal gland there are a few cells called the Inka cells that secrete and store preecdysis triggering hormone (PETH) and ecdysis triggering hormone (ETH). In addition, several other neuropeptides are involved in ecdysis: the above-mentioned corazonin from the paired group of ipsilateral neurosecretory cells in the brain, ion transport peptide (ITP), CCAP, MIP and FMRFamide peptides from the ventral ganglia. An outline of the major secretory locations of the ecdysial neuropeptides is shown in Fig. 5. ${ }^{71)}$ When the $20 \mathrm{E}$ is cleared, EH is released which initiates the release of all other neuropeptides, primarily PETH and ETH. ETH enhances further release of EH which in turn

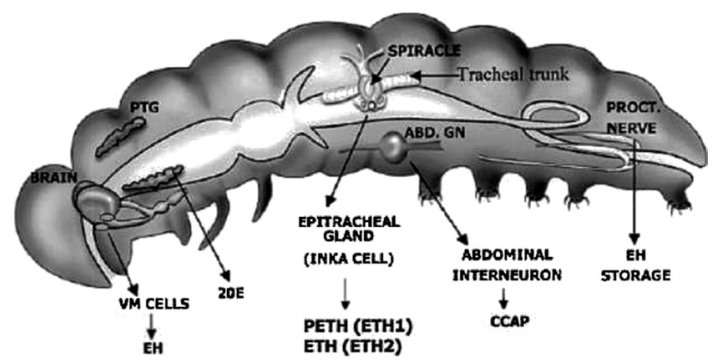

Fig. 5. The ecdysis cascade begins with the ventro-median cells (VM cells) secreting the eclosion hormone (EH) in the presence of $20 \mathrm{E}$, which is stored in the proctodeal nerves (proct. nerve) which serves as the neurohemal organ and is released in the absence of $20 \mathrm{E}$. It acts among other things on the Inka cells in the epitracheal glands, which secretes preecdysis triggering hormone (PETH or ETH1) and ecdysis triggering hormone (ETH or ETH2). These two hormones initiate the tracheal response, start the contractions, and induce the release of the crustacean cardioactivepeptide (CCAP) which completes the ecdysis. In the 5th instar spruce budworm, Choristoneura fumiferana, the process from 5th to 6th instar larva takes approximately $15 \mathrm{~min}$ (Reproduced with permission from the authors and the journal $^{71)}$ ).

empties the Inka cells of all the ETH. All these neuropeptides bind to their respective cognate receptors located in different neurons. As a result tracheal inflation followed by peristaltic movement of the body wall takes place, resulting in the ecdysis of the old cuticle. The new cuticle is elaborated, sclerotized and hardened with the help of another neurohormone, bursicon (a 173 amino acid protein belonging to the cystine knot family of growth factors), which is coexpressed with CCAP in the bilateral ventral neurons in the central nervous system of Drosophila. ${ }^{59,67-70,73)}$

The ecdysis cascade begins with the ventro-median cells (VM cells) secreting the eclosion hormone (EH) in the presence of 20E, which is stored in the proctodeal nerves (proct. nerve) which serves as the neurohemal organ and is released in the absence of $20 \mathrm{E}$ (Fig. 5). It acts among other things on the Inka cells in the epitracheal glands, which secretes preecdysis triggering hormone (PETH or ETH1) and ecdysis triggering hormone (ETH or ETH2). These two hormones initiate the tracheal response, start the contractions, and induce the release of the crustacean cardioactivepeptide (CCAP) which completes the ecdysis. In the 5th instar spruce budworm, Choristoneura fumiferana, the process from 5th to 6th instar larva takes approximately $15 \mathrm{~min}$.

\subsection{FMRFamides and FMRFamide-related peptides (FaRPS)}

Since the first discovery of this class of neuropeptides, the FMRFamides (peptides with 7 to 11 amino-acid residues Cterminally ending in phenylalanine $(\mathrm{F})$, methionine $(\mathrm{M})$, arginine(R), phenylalanine(F) amide), in the ganglia of a bivalve mollusc (Macrocallista nimbosa), which was cardioexcitatory, they have been found in almost all metazoans beginning with 
the coelenterates. ${ }^{13)}$ In all the invertebrates they evoke muscle contraction whereas in the vertebrates they act on the opioid systems. ${ }^{75,76)}$ The FMRFamide and FMRFamide-related peptides are collectively referred to as FaRPs. Insect FaRPs fall under 5 families that can be traced to 5 genes in Drosophila. $^{77)}$ Their C-terminal sequences are (1.) FMRFamide, (2.) GHMRFamide, (3.) FLRFamide, (4.) RVRFamide, and (5.) RLRFamide, RFamide being common to all of them. The last two types are also called neuropeptide $\mathrm{F}$ (NPY) and are treated separately in the following section. The typical FaRP preprohormone has a large numbers of copies of peptides ranging from 7 in the crayfish Procambarus clarkii $^{78)}$ to 9 in the Drosophila dFMRFamide gene product. ${ }^{79)}$

In Drosophila FMRFamides are cardioinhibitory, and in the larval stage they potentiate contraction of the body wall muscle. ${ }^{79)}$ These peptides are present throughout the central nervous system (Fig. 6). Seven of the 9 Drosophila FMRFamide peptides enhance nerve-evoked contractions in larval body wall muscles, ${ }^{90)}$ which suggest that the peptides may be functionally redundant. However, at least one of these peptides enhances synaptic potentials of one motor neuron but not another. ${ }^{92)}$ Thus, these peptides may modulate different chemical synapses in the larval body wall. In some insects FMRFamides increase the amplitude or frequency of heartbeats and in the blowfly induce salivary secretion. ${ }^{79,82}$ Although they are primarily involved in muscle excitation or inhibition, they also have a role in reproduction, feeding and other behaviors.

GHMRFamides are also known as sulfakinins, due to the presence of a sulfated tyrosine residue and resemble the mam-

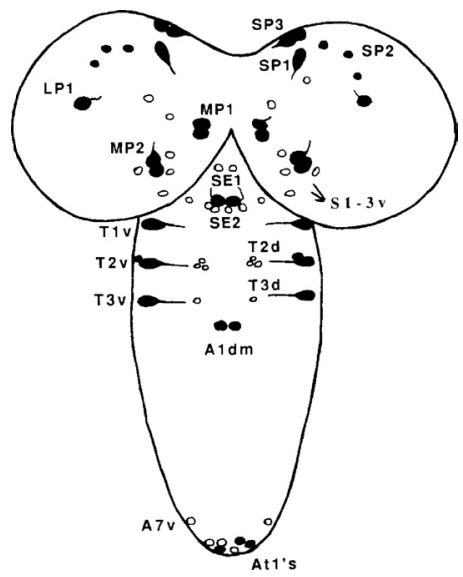

Fig. 6. FMRFamide-immunoreactive cell bodies in Drosophila melanogaster central nervous system. Filled symbols represent strongly-staining neurons and open symbols represent lightly-staining neurons. MP, medial protocerebrum; LP, lateral protocerebrum, $\mathrm{SP}$, superior proto-cerebrum; SE, subesophageal; S1-3 and T1-3, subesophageal and thoracic segments $1-3$, respectively; A1-7, abdominal segments $1-7$, respectively. Small case $d$ and $v$ indicate dorsal vs. ventral cell body positions; small case $\mathrm{m}$ indicates a medial cell body position (Reproduced with permission from the authors and the journal ${ }^{76}$ ). malian hormones gastrin and cholecystokinin. ${ }^{83)}$ They stimulate hindgut contraction in the cockroach, L. maderae, $\alpha$ amylase secretion in the midgut of the weevil, Rhynchophorus ferrugineus, ${ }^{84)}$ have a cardioacceleratory effect on Periplaneta, and reduced food intake in Schistocerca gregaria and Blatella germanica. ${ }^{85)}$ The Drosophila sulfakinin gene encodes a 128 amino-acid long protein processed into two GHMRFamide peptides (DSK I and II) and a peptide of unrelated sequence, DSK 0. ${ }^{79)}$

FLRFamides (also known as myosuppressins), are decapeptides with pleiotropic effects acting on a wide variety of organs. In insects they can inhibit contractions in the fore-, mid-, and hindgut, as well as the oviduct, inhibit writhing of Malpighian tubules, inhibit the release of $\mathrm{AKH}$, and potentiate contraction in a few locust skeletal muscles. ${ }^{76)}$ In the crayfish, $P$. clarkii, DRNFLRFamide is released from the pericardial organs and thought to function as a neurohormone. ${ }^{88)}$ It increases the amplitude of excitatory junction potentials (EJPs) in deep extensor muscles (DEMs) involving a presynaptic mechanism requiring calcium/calmodulin-dependent protein kinase, protein kinase $\mathrm{C}$ and cyclic nucleotide dependent protein kinases. ${ }^{86-89)}$ The synaptic modulation was shown to dependent on temperature and extracellular calcium. ${ }^{91,92)}$ DRNFLRFamide also induces contraction of superficial abdominal extensor muscles ${ }^{93}$ and enhances hindgut contractions. $^{94)}$

Receptors for FMRFamide-related peptides (FaRPs) have been cloned in two insect species, Drosophila and Anopheles. The Drosophila and Anopheles GPCRs for myosuppressins have been functionally characterized and found to be highly selective for this class of neuropeptide but not toward the FMRFamides. ${ }^{95,96)}$ The Drosophila FMRFamide receptor has also been cloned and stably expressed in Chinese hamster cells. Screening of the cells with a Drosophila peptide library revealed that FMRFamide peptide reacted with high affinity with the receptor. ${ }^{97)}$ Finally, the sulfakinin receptor of Drosophila has also been cloned and its ligand-binding properties examined. Strikingly, replacement of the sulfated tyrosine residue by a standard tyrosine in the ligand resulted in a 3000 fold decrease in the activity of the receptor. ${ }^{98)}$ These findings underscore the importance of highly precise lockand-key mechanisms in FaRPs mode of action, which probably warrants a review of the classification of these peptides based solely on sequence.

\subsection{Neuropeptide F (NPF) peptides}

NPFs are closely related to the FMRFamides, hence their inclusion in the FaRPs group. NPF was originally discovered in the tapeworm but later found in insects. The repertoire of NPF peptides is known from Drosophila owing to the full sequencing and annotation of its genome. Two NPF subclasses have been described: "short" NPFs (sNPFs) and "long" NPF (NPF). Two sNPFs exist in Drosophila (sNPF1 and 2) and are of sequence RLRFamide. In other insects, variations in C-ter- 
mini sequences have been found and can be PXLKTRFamide, PXLRLRFamide or RPRFamide, where $\mathrm{X}$ is a non-conserved amino acid. In Drosophila larvae, sNPFs are expressed in the neurons of the brain (dorsal posterior region) and in the ventral ganglion, while in adults they are present in the medulla and the mushroom bodies. ${ }^{99)}$ sNPFs regulate food intake and body size $\mathrm{e}^{99,100)}$ as determined by elegant ectopic overexpression and knockdown of the sNPF gene. The role of sNPFs on food intake might also be conserved in the hymenopteran Solenopsis invicta. ${ }^{101)}$

Long NPFs are homologs of the mammalian neuropeptide Y. A single gene has been identified in Drosophila, coding for 36 amino acid long, RVRFamide peptide. This NPF regulates diverse aspects of the feeding behavior, sensitivity to alcohol and reproduction. ${ }^{102,103)}$ Long NPF may also be involved in the synthesis and release of juvenile hormone or ecdysone. ${ }^{1)}$ GPCR for both short and long NPFs have been cloned and functionally characterized in heterologous cell expression assays. ${ }^{104,105)}$

\subsection{Ion transport peptide (ITP)}

ITP was identified in the corpora cardiaca of Schiztocerca gregaria and was found to stimulate $\mathrm{Cl}^{-}$ions across the locust hindgut. Its sequence is similar to that of the crustacean hyperglycemic hormone (CHHs), the molt inhibiting hormone (MIH), the vitellogenesis inhibiting hormone (VIH), and the mandibular organ inhibiting hormone (MOIHs). In locust and the silkworm, it is made up of 72 amino-acids and is amidated. In crustaceans, the $\mathrm{CHH}$ family is structurally diverse and serves several hormonal functions such as regulation of glucose level in the hemolymph, inhibition of ecdysteroids in the Y-organ, inhibition of methyl farnesoate in the mandibular organ, water regulation during crab ecdysis, and inhibition of vitellogenesis. $^{54)}$

\subsection{Leucokinins (LK) / myokinins (Kinins)}

The first kinins were isolated from the cockroach Leucophaea maderae and are part of a large family of invertebrate neuropeptides. Their $\mathrm{C}$-termini have the sequence $\mathrm{FX}_{1} \mathrm{X}_{2}$ WGamide where $\mathrm{X}_{1}$ is $\mathrm{F}, \mathrm{H}, \mathrm{N}, \mathrm{S}$ or $\mathrm{Y}$ and $\mathrm{X}_{2}$ is $\mathrm{A}, \mathrm{P}$ or $\mathrm{S}$. They were originally found to stimulate contraction of the cockroach hindgut. Later, members of the kinin family were also found to induce secretion in the Malpighian tubule. They have been found in the neurons and neurosecretory cells of the brain and the ventral ganglia. ${ }^{106}$

2.18. Pyrokinin (PK) related peptides such as locust myotropin, peromone biosynthesis activating neuropeptide(PBAN), diapause hormone (BomDH), melanization and reddish coloration hormone (MRCH)

Leucophaea maderae pyrokinin was the first one to be studied and has an N-terminal pyroglutamate residue and is myostimulatory in the hind gut. The C-terminus sequence is FX-
PRLamide and has been called pyrokinins or myotropins. Pyrokinins are known to occur in insects and crustaceans. At least two genes coding for pyrokinins have been identified in Drosophila. ${ }^{33)}$ They are involved in modulation of rhythmic motor activity. ${ }^{107)}$ The extended peptides of pyrokinins are the pheromone biosynthesis activating neuropeptide(PBAN), diapause hormone $(\mathrm{BomDH})$, melanization and reddish coloration hormone $(\mathrm{MRCH})$. These members of the pyrokinin family are produced by the suboesophageal ganglia. PBAN exerts its effect on the pheromone gland and a GPCR has been found in the pheromone gland of Helicoverpa zea and $B$. mori. ${ }^{1)}$ Induction of color changes in larvae by $\mathrm{MRCH}$ and induction of diapause in the eggs of Bombyx mori by $\mathrm{BomDH}$ are the other functions observed.

\subsection{Tachykinin (or neurokinin) related peptides (TRPS)} Tachykinin (or neurokinin) related peptides have been extensively studied mainly because they occur across phyla including the chordates where they have been well investigated. A Drosophila gene encoding multiple TRPs has been identified. They have been isolated from insects and crustaceans. A Drosophila tackykinin receptor (DTKR) was expressed in Xenopus oocytes and tested against both vertebrate and insect tackykinins and only the latter showed any response. A second fruitfly receptor was cloned and expressed in a stable mammalian cell line. A third TRP receptor (TRPR) from the stable fly has been cloned. ${ }^{1)}$ TRPs are distributed in the brain and ventral nerve cord in insects. In the crayfish and lobster they are present in the olfactory and optic lobes of the brain as well as in the stomatogastric system. In crustaceans the TRPs are colocalized with the inhibitory neurotransmitter, GABA. There are many TRP isoforms in insects but not in crustacea. They are myostimulatory in hindgut, foregut, midgut and the oviduct; myomodulatory in the tibial skeletal muscle; induce diuresis or fluid secretion in the Malpighian tubule; AKH release from the corpora cardiaca; induce pheromone biosynthesis in the silkworm. It is readily apparent that TRPs have a multiplicity of functions in insects and crustacea. The enzymatic desensitization of TRPRs has been studied in insects.

\subsection{SIFamide peptide}

A little known Drosophila gene has been annotated as a neuropeptide precursor gene encoding the predicted peptide, PPFNGSIFamide. ${ }^{33)}$ A related fleshfly peptide, LFamide was found to be myotropic and localized in the median neurosecretory cells of the brain.

\subsection{Insulin-like peptide}

Insulin-like peptides are produced by neurons and neurosecretory cells in insects and may act as neuronal or neuroendocrine signalling systems and are therefore treated here as neuropeptides. Insulin-like peptides, insulin-like growth factors (IGFs) and bombyxin make this group of neuropeptides. 
Insulin-like peptide together with the insulin receptor appear to be important in growth and development especially in the assessment of critical size. Larvae initiate the molting cycle when they reach a critical size at which time the prothoracicotropic hormone (PTTH) is released from the brain and the molting cascade ensues (ecdysone secretion, etc.). The critical size is determined by the size of the prothoracic gland. A TOR (target of rapamycin)-mediated nutrient sensor in the fat body detects nutrient availability, and regulates insulin signaling in peripheral tissues, which in turn controls larval growth rates. ${ }^{108)}$ Overexpression of the insulin receptor results in increase in growth. It is likely that the insulin-like peptides are released into the hemolymph in a nutrition dependent manner as starvation reduces the insulin level and as a result growth is slower. ${ }^{109)}$ Drosophila insulin receptor (DIR) has been characterized and is made of 4 subunits, $2 \alpha$ and $2 \beta$ and the former comprise the insulin binding site. It is one of the few receptors discussed here which is not a GPCR, but a member of the superfamily of receptor tyrosine kinases. ${ }^{110)}$

\subsection{Proctolin}

Proctolin is a myotropic pentapeptide (of sequence RYLPT) that acts on muscles and in conjunction with glutamate can act as both a neuromodulator and a neurotransmitter. ${ }^{11,112)}$ It was first isolated from $125 \mathrm{~kg}$ of whole cockroaches which yielded $180 \mu \mathrm{g}$ of bioactive material! ${ }^{113)}$ Proctolin is produced by a wide number of glands and nervous tissues in arthropods. It is present in the central nervous systems of decapod crustaceans, where it is thought to act as a neurotransmitter, in motor neurons, where it acts as a co-transmitter, and in neurohaemal organs, notably the pericardial organs, which are thought to release proctolin as a neurohormone. ${ }^{114-117)}$ Proctolin is associated with crustacean stomatogastric nervous systems and hindgut, ${ }^{11-120)}$ suggesting a role in digestion. Proctolin is present in the cockroach central nervous system ${ }^{121)}$ and in the lateral neurosecretory cells (3 pairs) in the brain of Drosophila where it is coexpressed with corazonin and a cardioacceleratory neuropeptide. It is a myotropic neuropeptide that acts on visceral, skeletal and heart muscles and in conjunction with glutamate as a neuromodulator or cotransmitter. ${ }^{111,112,122)}$ In addition to innervated muscular tissue and neurons, hemolymph-borne proctolin can reach non-innervated tissues such as the Malpighian tubules to exert influence on urine secretion. ${ }^{123}$ It is also associated with color change in Locusta.

Like most secreted peptides, mature proctolin is generated in a stepwise proteolytic maturation process: first as preproproctolin then processed to proproctolin and finally cleaved into proctolin in the trans Golgi network. The proctolin receptor has been fully sequenced and is a cAMP type Family A GPCR. ${ }^{124,125)}$

\subsection{Arginine-vasopressin like peptide (AVP)}

It was first isolated from the central nervous system (CNS) of the locust and found to be very similar to the vertebrate vasopressin and hence named arginine-vasopressin like peptide (AVP). It has a sequence of CLITNCPRGamide and can also exist as a homodimer in the antiparallel way joined by disulfide bridges. It seems to function as a light related neuropeptide for diurnal activity of the locust. ${ }^{1)}$

\subsection{Orcokinins (ORKs)}

Orcokinins (ORKs) are highly conserved myotropic neuropeptides found in the brain of crustaceans and insects. Their sequence, NFDEIDRSGFGFN, in crustaceans is well conserved. Insects appear to have NFDEIDR common with Crustaceans. ${ }^{126)}$

\subsection{Neuroparsins (NPS)}

These small proteins or peptides are about $8-\mathrm{kDa}$ and are present primarily in the pars intercerebralis and corpora cardiaca as well as in other tissues to a lesser extent. They are pleiotropic and have anti $\mathrm{JH}$, antidiuretic, neuritogenic effects as well as a regulatory role in reproduction. They bind to vertebrate and molluscan insulin like growth factor binding proteins (IGFBP) suggesting an insulin related function. ${ }^{30,127)}$

While we have endeavoured our best to include almost all the neuropeptides for which a function has been either determined or suggested and at the same time maintain some semblance of brevity, it is entirely possible that we have overlooked some. In the years to come, in this rapidly advancing field, there will be many new and exciting ones added to our list. Some of them would undoubtedly be in the areas of behavior, nutrition, and circadian clock.

\section{Discussion and Conclusions}

It is incredibly amazing to mentally visualize the myriad of autonomous functions taking place within an organism at any given time including the movements of the various ducts and the secretions of different glands. Almost all these acts are performed by a signal carried by a neuropeptide to its cognate receptor in the effector organ. Starting with alternative splicing at the DNA level and often progressively increasing in number at the RNA and protein levels, many neuropeptide genes end up producing several neuropeptides. Many of them have taken on multiple functions and redundancies are not uncommon as "fail safe" mechanisms. The net result is a complex array of neuropeptides that crisscross the entire complex of internal physiology, making any attempt to classify them along functional lines extremely arduous. We have provided an anthology of the salient features of neuropeptides in two classes of the phylum Arthropoda and have followed the footsteps of other authors before us. ${ }^{1,2,7,10)}$

Neuropeptides and their receptors have practical applications as well. Many of the newer drugs developed in recent years for treatment of human diseases are based on neuropeptides and their cognate receptors and this area of research is a favourite target for the pharmaceutical industry for drug dis- 
covery. ${ }^{16,17,128,129)}$ Neuropeptide based biorational insecticides for pest management is a field that appears to be ready for exploitation. $^{130,131)}$

Most of the original studies on neuropeptides are based on immunodetection with polyclonal antibodies. In order to be certain that the identification is absolute, confirmation with another procedure is necessary. With the advent of sensitive 2-dimensional gel electrophoresis combined with mass spectrometry it is now possible to separate and identify peptides with certainty. In silico analysis of genomic data allows us to identify gene sequences of interest such as GPCRs. By judiciously combining these techniques, it is now possible to generate reliable new information that will help us resolve many of the unsolved mysteries of the past. In the next few years we should look forward to the publication of an array of new information on neuropeptide structure and physiology.

\section{References}

1) I. Claeys, J. Poels, G. Simonet, V. Franssens, T. Van Loy, M. B. Van Hiel, B. Breugelmans and J. V. Broeck: Vitamins and Hormones 73, 217-278 (2005).

2) G. Gade, K-H. Hoffmann and J. H. Spring: Physiol. Rev. 77, 963-1032 (1997).

3) F. Hauser, G. Cazzamali, M. Williamson, W. Blenau and C. J. P. Grimmelikhuijzen: Neurobiol. 80, 1-19 (2006).

4) F. Hauser, M. Williamson, G. Cazzamali and C. J. P. Grimmelikhuijzen: Proteomics 4, 321-330 (2006).

5) G. M. Holman, R. J. Nachman and M. S. Wright: Ann. Rev. Entomol. 35, 201- 217 (1990).

6) D. A. Lovejoy: "Neuroendocrinology: An Integrated Approach," John Wiley \& Sons, Ltd., Hoboken, NJ, USA, 2005.

7) H. G. Marco: International Congress Series 1275, 126-133 (2004).

8) J. J. Menn, T. J. Kelly and E. P. Masler (eds.): "Insect Neuropeptides: Chemistry, Biology and Action," ACS Symposium Series 453. American Chemical Society, Washington, DC, pp. 237-251, 1991.

9) D. R. Nässel: Naturwissenschaften 87, 439-449 (2000).

10) D. R. Nässel: Prog. Neurobiol. 68, 1-84 (2002).

11) Y. Park and M. E. Adams: "Comprehensive Insect Molecular Science," Vol. 5, ed. by L. I. Gilbert, K. Iatrou and S. Gill, Elsevier, Oxford, pp. 143-171, 2005.

12) O. Sakarya, K. A. Armstrong, M. Adamska, M. Adamski and I-F. Wang: PloS ONE 2: e506. doi:10.1371/journal.pone. 0000506 (2007).

13) C. J. P. Grimmelikhuijzen, G. J. Dockray and L. P. C. Schot: Histochemistry 73, 499-508 (1982).

14) C. J. P. Grimmelikhuijzen, K. Rinehartt, E. Jacob, D. Graff, R. K. Reinscheid, H-P. Nothacker and A. L. Staleyt: Proc. Natl. Acad. Sci. U.S.A. 87, 5410-5414 (1990).

15) J. C. R. Cardoso, V. C. Pinto, F. A. Vieira, M. S. Clark and D. M. Power: BMC. Evolutionary Biology 6, 108-124 (1990).

16) R. J. Lefkowitz: Trends. Pharmacol. Sci. 25, 413-422 (2004).

17) R. J. Lefkowitz: Acta Physiologica 190, 9-19 (2007).

18) G. A. Cottrell: J. Exp. Biol. 200, 2377-2386 (1997).

19) E. Linguelia, E. Deval and M. Lazdunski: Peptides 27,
1138-1152 (2006).

20) K. L. Pierce, R. T. Premont and R. J. Lefkovitz: Nature Rev. Mol. Cell Biol. 27, 639-650 (2002).

21) M. C. Gershengorn and R. Osman: Endocrinology 142, 2-10 (2001).

22) W. K. D. Kroeze, D. J. Sheffler and B. L. Roth: J. Cell. Sci. 116, 4867-4869 (2003).

$23)$ S. S. G. Ferguson: Pharmacol. Rev. 53, 1-24 (2001).

24) S. G. Lee and D. L. Mykles: Integrative and Comp. Biol. 46, 965-977 (2006).

25) L. M. Riddiford, P. Cherbas and J. W. Truman: Vitamins and Hormones 60, 1-73 (2001).

26) E. S. Chang, S. A. Chang and E. P. Mulder: Amer. Zool. 41, 1090-1097 (2001).

27) N. Audsley and R. J. Weaver: Regulatory Peptides 116, 127-137 (2003).

28) S. S. Dekeyser, K. K. Kutz-Naber, J. J. Schmidt, G. A. BarrettWilt and L. Li: J. Proteome Res. 6, 1782-1791 (2007).

29) R. Kwok and S. S. Tobe: Peptides 27, 590-596 (2006).

30) L. Badisco, I. Claeys, T. V. Loy, M. V. Hiel, V. Franssens, G. Simonet and J. V. Broeck: Gen. Comp. Endocrinol. Doi: 10.1016/j.ygcen. 2007.03.008 (2007).

31) H. Schooneveld, G. I. Tesser, J. A. Veenstra and H. M. Romberg-Privee: Cell Tissue Res. 230, 67-76 (1983).

32) D. J. Van der Horst, W. J. A. Van Marrewijk and J. H. B. Diederen: Int. Rev. Cytol. 211, 179-240 (2001).

33) R. S. Hewes and P. H. Taghert: Genome Res. 11, 1126-1142 (2001).

34) R. Ziegler, R. D. Jasensky and H. Morimoto: Regul. Pept. 57, 329-338 (1995).

35) D. J. Van der Horst: Comp. Biochem. Physiol. B. 136, 217-226 (2003).

36) D. Wicher, C. Walther and C. Wicher: Prog. Neurobiol. 64, 431-525 (2001).

37) M. A. Verde, C. Barriga-Montoya and B. Fuentes-Pardo: Comp. Biochem. Physiol. A Mol. Integr. Physiol. 147, 983-992 (2007).

38) B. Stay and S. S. Tobe: Annu. Rev. Entomol. 52, 277-299 (2007).

39) J. Jorge-Rivera and Y. E. Marder: J. Exp. Biol. 200, 2937-2946 (1997).

40) H. Dircksen, P. Skiebe, B. Abel, H. Agricola, K. Buchner, J. E. Muren and D. R. Nassel: Peptides 20, 695-712 (1999).

41) R. Kwok, J. R. Zhang and S. S. Tobe: J. Insect Physiol. 51, 367-378 (2005).

42) M. M. Elekonich and F. M. Horodyski: Peptides 24, 1623-1632 (2003).

43) W. G. Goodman and N. A. Granger: "Comprehensive Insect Molecular Science," Vol. 3, ed. by L. I. Gilbert, K. Iatrou and S. Gill, Elsevier, Oxford, pp. 319-408, 2005.

44) H. Kataoka, A. Toschi, J. P. Li, R. L. Carney, D. A. Schooley and S. J. Kramer: Science 243, 1481-1483 (1989).

45) Z. Sheng, L. Ma, M. X. Cao, S. Li and R. J. Jiang: Mol. Biol. 37, 90-96 (2007).

46) P. F. Truesdell, P. M. Koladich, H. Kataoka, K. Kojima, A. Suzuki, J. McNeil, A. Mizoguchi, S. S. Tobe and W. G. Bendena: Mol. Biol. 30, 691-702 (2000). 
47) M. Abdel-latief, M. Meyering-Vos and K. H. Hoffmann: Insect Biochem. Mol. Biol. 33, 467-476 (2003).

48) Y. Li, G. C. Unnithan, J. A. Veenstra, R. Feyereisen and F. G. Noriega: J. Exp. Biol. 206, 1825-1832 (2003).

49) L. Paemen, A. Tips, L. Schoofs, P. Proost, J. Van Damme and A. De Loof: Peptides 12, 7-10 (1991).

50) K. Y. Lee, F. M. Horodyski and M. E. Chamberlin: J. Exp. Biol. 201, 3067-3074 (2002).

51) M. B. Aguilar, R. Falchetto, J. Shabanowitz, D. F. Hunt and A Huberman: Peptides 16, 1375-1383 (1995).

52) M. L. Fanjul-Moles: Comp. Biochem. Physiol. Part C. 142, 390-400 (2006)

53) G. A. LeBlanc: Ecotoxicology 16, 61-81 (2007).

54) R. Keller: Experientia 48, 439-448 (1992).

55) S. Waddell and W. G. Quinn: Annu. Rev. Neurosci. 24, 1283-1309 (2001).

56) D. Yu, A. C. Keene, A. Srivatsan, S. Waddell and R. L. Davis: Cell 123, 945-957 (2005).

57) C. Wegener, Z. Herbert, M. Eckert and R. Predel: Peptides 23, 605-611 (2002).

58) Y. J. Hua, J. Ishibashi, H. Saito, A. I. Tawfik, M. Sakakibara, Y. Tanaka, R. Derua, E. Waelkens, G. Baggerman and A. De Loof: J. Insect Physiol. 46, 853-859 (2000).

59) Y-J. Kim, I. Spalovska-Valachova, K-H. Cho, I. Zitnanova, Y. Park, M. E. Adams and D. Zitnan: Proc. Natl. Acad. Sci. U.S.A. 101, 6704-6709 (2004).

60) D. Zitnan, Y-J. Kim, I. Zitnanova, L. Roller and M. E. Adams: Gen. Comp. Endocrinol. Doi:10.1016/j.ygcen.2007.04.002 (2007).

61) J. Stangier, C. Hilbich, K. Beyreuther and R. Keller: Proc. Natl. Acad. Sci. U.S.A. 84, 575-579 (1987).

62) G. Cazzamali, F. Hauser, S. Kobberup, M. Williamson and C. J. P. Grimmelikhuijzen: Biochem. Biophys. Res. Commun. 303, 146-152 (2003)

63) L. F. Harthoorn, R. C. Oudejans, J. H. Diederen and D. J. Van der Horst: Peptides 23, 629-634 (2002).

64) H. Kataoka, R. G. Troetschler, J. P. Li, S. J. Kramer, R. J. Cesarin and D. A. Schooley: Proc. Natl. Acad. Sci. U.S.A. 86, 2976-2980 (1989).

65) J. A. Veenstra and H. H. Hagedorn: Cell Tissue Res. 266, 359-364 (1991)

66) K. Furuya, R. J. Milchak, K. M. Schegg, J. R. Zhang, S. S. Tobe, G. Coast and D. A. Schooley: Proc. Natl. Acad. Sci. U.S.A. 97, 6469-6474 (2000).

67) Y. J. Kim, D. Zitnan, K. H. Cho, D. A. Schooley, A. Mizoguchi and M. E. Adams: Proc. Natl. Acad. Sci. U.S.A. 103, 14211-14216 (2006).

68) Y. J. Kim, D. Zitnan, C. G. Galizia, K. H. Cho and M. E. Adams: Current Biol. 16, 1395-1407 (2006)

69) J. W. Truman: Vitamins and Hormones 73, 1-30 (2005).

70) D. Zitnan and M. E. Adams: "Comprehensive Insect Molecular Science," Vol. 3, ed. by L. I. Gilbert, K. Iatrou and S. Gill, Elsevier, Oxford, pp. 1-60, 2005.

71) A. Retnakaran, B. M. Arif and Q. Feng: Arch. Insect Biochem. Physiol. 54, 187-99 (2003).

72) R. Rybczynski: "Comprehensive Insect Molecular Science," Vol. 3, ed. by L. I. Gilbert, K. Iatrou and S. Gill, Elsevier, Ox- ford, pp. 61-123, 2005.

73) E. M. Dewey, S. L. McNabb, J. Ewer, G. R. Kuo, L. Christina, C. L. Takanishi, J. W. Truman and H-W. Honegger: Current Biol. 14, 1208-1213 (2004).

74) D. A. Price and M. J. Greenberg: Prep. Biochem. 7, 261-281 (1977).

75) A. J. Mercier and R. T. Russenes: Biol. Bull. 182, 333-340 (1992).

76) P. H. Taghert: Microsc. Res. Tech. 45, 80-95 (1999).

77) J. Merte and R. I. Nichols: Peptides 23, 209-220 (2002).

78) Y. Yasuda-Kamatani and A. Yasuda: J. Comp. Neurol. 496, 135-147 (2006).

79) R. Nichols: Annu. Rev. Entomol. 48, 485-503 (2003).

$80)$ R. S. Hewes, E. C. Snowdeal, M. Saltoe and P. H. Taghert: J. Neurosci. 18, 7138-7151 (1998).

81) T. W. Dunn and A. J. Mercier: Peptides 26, 269-276 (2005).

82) H. Duve, A. H. Johnsen, J. C. Sewell, A. G. Scott, I. Orchard, J. F. Rehfeld and A. Thorpe: Proc. Natl. Acad. Sci. U.S.A. 89, 2326-2330 (1992).

83) R. Predel, W. Brandt, R. Kellner, J. Rapus, R. J. Nachman and G. Gäde: Eur. J. Biochem. 263, 552-560 (1999).

84) R. J. Nachman, W. Giard, P. Favrel, T. Suresh, S. Sreekumar and G. M. Holman: Ann. N.Y. Acad. Sci. 814, 335-338 (1997).

$85)$ J. L. Maestro, R. Aguilar, N. Pascual, M. L. Valero, M. D. Piulachs, D. Andreu, I. Navarro and X. Bellés: Eur. J. Biochem. 268, 5824-5830 (2001).

86) A. Badhwar, A. D. Weston, J. Murray and A. J. Mercier: Peptides 27, 1281-1290 (2006)

87) R. W. Friedrich, G. F. Molnar, M. Schiebe and A. J. Mercier: J. Neurophysiol. 79, 1127-1131 (1998).

88) A. J. Mercier, A. Badhwar, A. D. Weston and M. Klose: "Physiology of the Crustacean Nervous System," ed. by K. Wiese and S. M. Heidelberg, Springer-Verlag, Heidelberg, pp. 49-62, 2001.

89) K. Noronha and A. J. Mercier: Brain Res. 673, 70-74 (1995).

90) M. P. Skerrett, P. Quigley, A. Peaire and A. J. Mercier: J. Exp. Biol. 198, 109-116 (1995).

91) R. W. Friedrich, P. A. Quigley, M. Srivastava, M. Skerrett and A. J. Mercier: Neurosci. Lett. 169, 56-58 (1994).

92) T. W. Dunn and A. J. Mercier: J. Neurophysiol. 89, 1807-1814 (2003)

93) P. A. Quigley and A. J. Mercier: Comp. Biochem. Physiol. 118A, 1313-1320 (1997)

94) J. Lee and A. J. Mercier: Peptides 23, 1751-1757 (2002).

95) S. Schöller, M. Belmont, G. Cazzamali, F. Hauser, M. Williamson and C. J. P. Grimmelikhuijzen: Biochem. Biophys. Res. Commun. 327, 29-34 (2005).

96) K. Egerod, E. Reynisson, F. Hauser, G. Cazzamali, M. Williamson and C. J. P. Grimmelikhuijzen: Proc. Natl. Acad. Sci. U.S.A. 100, 9808-9813 (2003).

97) G. Cazzamali and C. J. P. Grimmelikhuijzen: Proc. Natl. Acad. Sci. U.S.A. 99, 12073-12078 (2002).

98) T. M. Kubiak, M. J. Larsen, K. J. Burton, C. A. Bannow, R. A. Martin, M. R. Zantello and D. E. Lowery: Biochem. Biophys. Res. Commun. 291, 313-320 (2002).

99) K-S. Lee, K-H. You, J-K. Choo, Y-M. Han and K. Yu: J. Biol. Chem. 279, 50781-50789 (2004). 
100) S. F. Garczynski, M. R. Brown and J. W. Crim: Peptides 27, 575-582 (2006).

101) M-E. Chen and P. V. Pietrantonio: Arch. Insect Biochem. Physiol. 61, 195-208 (2006).

102) Q. Wu, Z. Zhao and P. Shen: Nat. Neurosci. 8, 1350-1355 (2005).

103) T. Wen, C. A. Parrish, D. Xu, Q. Wu and P. Shen: Proc. Natl. Acad. Sci. U.S.A. 102, 2141-2146 (2005).

104) S. F. Garczynski, M. R. Brown, P. Shen, T. F. Murray and J. W. Crim: Peptides 23, 773-780 (2002).

105) S. F. Garczynski, J. W. Crim and M. R. Brown: Peptides 26, 99-107 (2005).

106) J. A. Veenstra, J. M. Pattillo and D. H. Petzel: J. Biol. Chem. 272, 10402-10407 (1997).

107) S. R. Saideman, M. Ma, K. K. Kutz-Naber, A. Cook, P. Torfs, L. Schoofs, L. Li and M. P. Nusbaum: J. Neurophysiol. 97, 579-595 (2007).

108) C. K. Mirth and L. M. Riddiford: Bioessays 29, 344-355 (2007).

109) I. Claeys, G. Simonet, J. Poels, T. Van Loy, L. Vercammen, A. De Loof and J. Vanden Broeck: Peptides 23, 807-816 (2002).

110) R. Fernandez-Almonacid and O. M. Rosen: Mol. Cell. Biol. 7 , 2718-2727 (1987).

111) A. B. Lange: Peptides 23, 2063-2070 (2002).

112) A. B. Lange, I. Orchard and F. M. Barrett: J. Insect. Physiol. 34, 379-386 (1988).

113) A. N. Starratt and B. E. Brown: Life Sci. 17, 1253-1256 (1975).

114) C. A. Bishop, J. J. Wine and M. O'Shea: J. Neurosci. 4, 2001-2009 (1984).

115) T. L. Schwarz, G. M. Lee, K. K. Siwicki, D. G. Standaert and
E. A. Kravitz: J. Neuroscience 4, 1300-1311 (1984).

116) K. K. Siwicki, B. S. Beltz, T. L. Schwarz and E. A. Kravitz: Peptides 6, 393-402 (1985).

117) K. K. Siwicki and C. A. Bishop: J. Comp. Neurol. 22, 435-453 (1986).

$118)$ E. S. Marder, S. L. Hooper and K. K. Siwicki: J. Comp. Neurol. 243, 454-467 (1986).

119) A. J. Mercier, A. B. Lange, V. TeBrugge and I. Orchard: Can. J. Zool. 75, 1208-1225 (1997).

120) P. Skiebe, C. Dietel and M. Schmidt: J. Comp. Neurol. 414, 511-532 (1999).

121) C. A. Bishop and M. O'Shea: J. Comp. Neurol. 207, 223-238 (1982).

122) M. E. Adams and M. O'Shea: Science 221, 286-289 (1983).

123) I. Orchard, J. H. Belanger and A. B. Lange: J. Neurobiol. 20, 470-496 (1989).

124) R. E. Isaac, C. A. Taylor, Y. Hamasaka, D. R. Nassel and A. D. Shirras: Invert. Neuroscience 5, 51-64 (2004).

$125)$ C. A. M. Taylor, A. M. E. Winther, R. J. Siviter, A. D. Shirras, R. E. Isaac and D. R. Nassel: J. Neurobiol. 58, 379-391 (2004).

126) S. Hofer, H. Dircksen, P. Tollback and U. Homberg: J. Comp. Neurol. 490, 57-71 (2005).

127) I. Claeys, B. Breugelmans, G. Simonet, V. Franssens, S. V. Soest and J. V. Broeck: Arch. Insect Biochem. Physiol. 62, 107-115 (2006).

128) L. D. Fricker: AAPS Journal 7, 449-455 (2005).

129) E. Kostenis, M. Waelbroeck and G. Milligan: Trends Pharmacol. Sci. 26, 595-602 (2005).

130) M. Altstein: J. Mol. Sci. 22, 147-157 (2004).

131) G. Gade and G. J. Goldsworthy: Pest. Manag. Sci. 59, 1063-1075 (2003). 